\title{
Method of dissecting edible snails of the genus Cornu
}

\author{
JERZY ZIĘTEK, MONIKA ZIOMEK*, ANNA WILCZYŃSKA
}

\author{
Department of Epizoology and Clinic of Infectious Diseases, Faculty of Veterinary Medicine, \\ University of Life Sciences in Lublin, Głęboka 30, 20-612 Lublin, Poland \\ *Department of Food Hygiene of Animal Origin, Faculty of Veterinary Medicine, \\ University of Life Sciences in Lublin, Akademicka 12, 20-950 Lublin, Poland
}

\section{Ziętek J., Ziomek M., Wilczyńska A. \\ Method of dissecting edible snails of the genus Cornu}

Summary

Snails of the genus Cornu are farm-raised as edible molluscs. Dissection is one of the basic diagnostic tests available in the breeding of these animals, used to determine the cause of death or disease, and to collect material for further laboratory tests. The aim of this article was to present a method for the dissection of snails for veterinary use based on the experience gained from 200 molluse dissections, and to present a short description of the anatomical structure of snails. The method described is characterized by its speed and simplicity. The observations made during the dissection, as presented in the article provide valuable diagnostic information for veterinarians responsible for care on snail farms.

Keywords: Cornu aspersum aspersum, snail anatomy, snail dissection, edible snail

In the past, interest in snails as part of veterinary practice was limited to their role as intermediate hosts in the development cycles of parasites. As farmed animals, their role and importance have increased significantly over the past few years, and they have become the subject of scientific research focused on their living conditions, health assessment and the possibility of using products derived from them. Particularly important are the farm breeds from which raw materials are obtained for the food industry (meat and eggs) and the cosmetics industry (mucus) (1). Grey snails belonging to the genus Cornu are among the most popular land snails consumed in Europe and kept under farming conditions. Two subspecies of snails of the genus Cornu are used as farm breeds, the small grey Cornu aspersum aspersum (CAA) and the large grey Cornu aspersum maxima (CAM). These snails are also referred to by their common names by Polish breeders, based on translations of their French names, i.e. petit-gris, müller or "Mediterranean snail" for CAA and gros-gris, maxima or "African snail" for CAM (8). In order to ensure good health and the safety of raw materials used as food, production businesses which rear, breed and subsequently place snails on the market for human consumption are subject to official veterinary supervision by the Veterinary Inspection. Intensive breeding of snails poses a risk of pathogen accumulation in the breeding environment, which cause increased mortality rates and losses in breeding.
Detailed laboratory tests and dissections are among the basic diagnostic tests performed in the breeding of these animals, to determine the causes of disease and falls as well as to collect material for further laboratory tests. The aim of this study is to present a method of dissecting snails for diagnostic purposes, based on the experience gained from the dissection of 200 snails, combined with a short description of the anatomical structure of the snail. The method is characterized by ease and short duration, with a full picture of the changes taking place at the same time. The observations made during the dissection provide valuable diagnostic information for veterinarians in caring for snail farms.

\section{Material and methods}

A total of 200 snails were used for dissection: 100 CAA and 100 CAM, from 3 farms located in Poland. Of these, 180 were dead animals sent to the Clinic of Infectious Diseases, while the remaining 20 animals were euthanized with pentobarbital administered to the main vessel (7). The dissections were performed in order to determine the causes of animal deaths on farms.

The first stage of the study was a macroscopic evaluation of the condition of the animals, including the shells, as well as an evaluation of the epiphragm - a semi-transparent membrane produced by the animals during hibernation or aestivation. The removal of the shells (Fig. 1a) made it possible to assess the condition of the soft body. Snails of the genus 

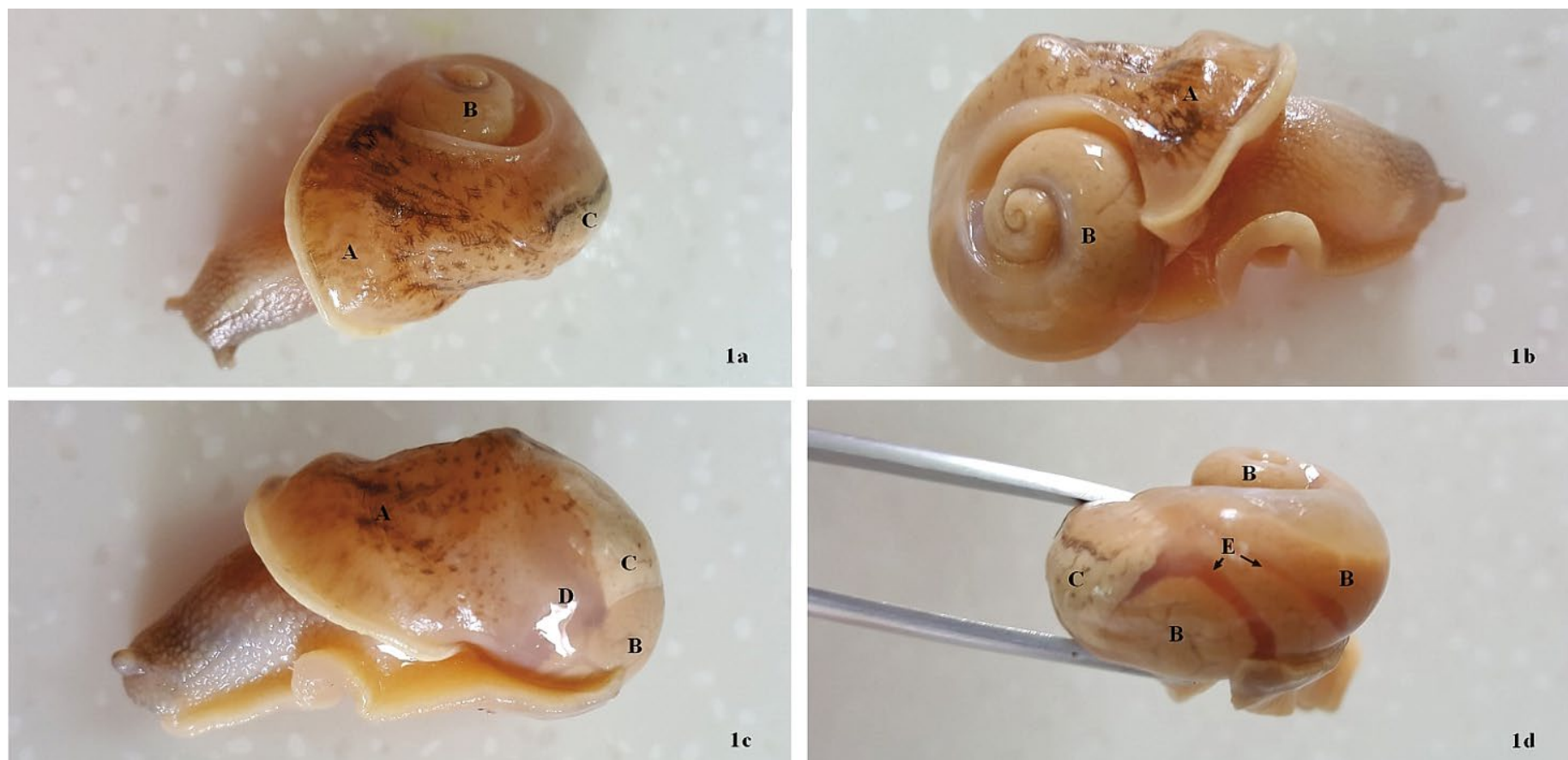

Fig. 1. The external surface of the pallial lung (A), hepatopancreas (B), kidney (C), heart (D), intestinal loops (E)

Cornu consist of two main parts: the characteristic shell forming an outer skeleton and a soft body connected to the shell by a columellar muscle. The shell is made of calcium carbonate in the form of crystalline calcite and aragonite, and a conchiolin protein specific for molluses to act as a mineral binder. On the outside it is covered with a thin horny layer containing dyes, such as carotenoids, porphyrins, melanin and indigo. The shell is formed around the columella, a thin axial cylinder, around which the shells are twisted. This is where the columellar muscle is attached, with distal insertions anchored in the foot of the animal. This muscle is responsible for pulling the animal's body into the shell. The mouth of the shell is an opening with a rim. In the case of sexually mature snails of the genus Cornu (C. aspersum aspersum), the shell opening becomes folded to form a lip. The shape, colour and size of the shells, apart from genetic conditions, may be important indicators of the health, nutrition and living conditions of the snails. The soft body of a snail can be seen when it is removed from the shell, and comprises three parts: a poorly distinguishable head, a muscular leg and a visceral sac containing internal organs. The visceral sac is separated from the leg by a muscular prominence called a mantle. The leg is formed by smooth muscles covered with skin rich in mucous glands. There are two pairs of tentacles on the head part of the leg. On the first one are vestibular eyes, which have many analogies with the structure of the eye (presence of lens, cornea, vitreous body and retina). The second pair of tentacles acts as an auxiliary organ reacting mainly to touch, and has the function of an olfactory organ. The movement of the snail
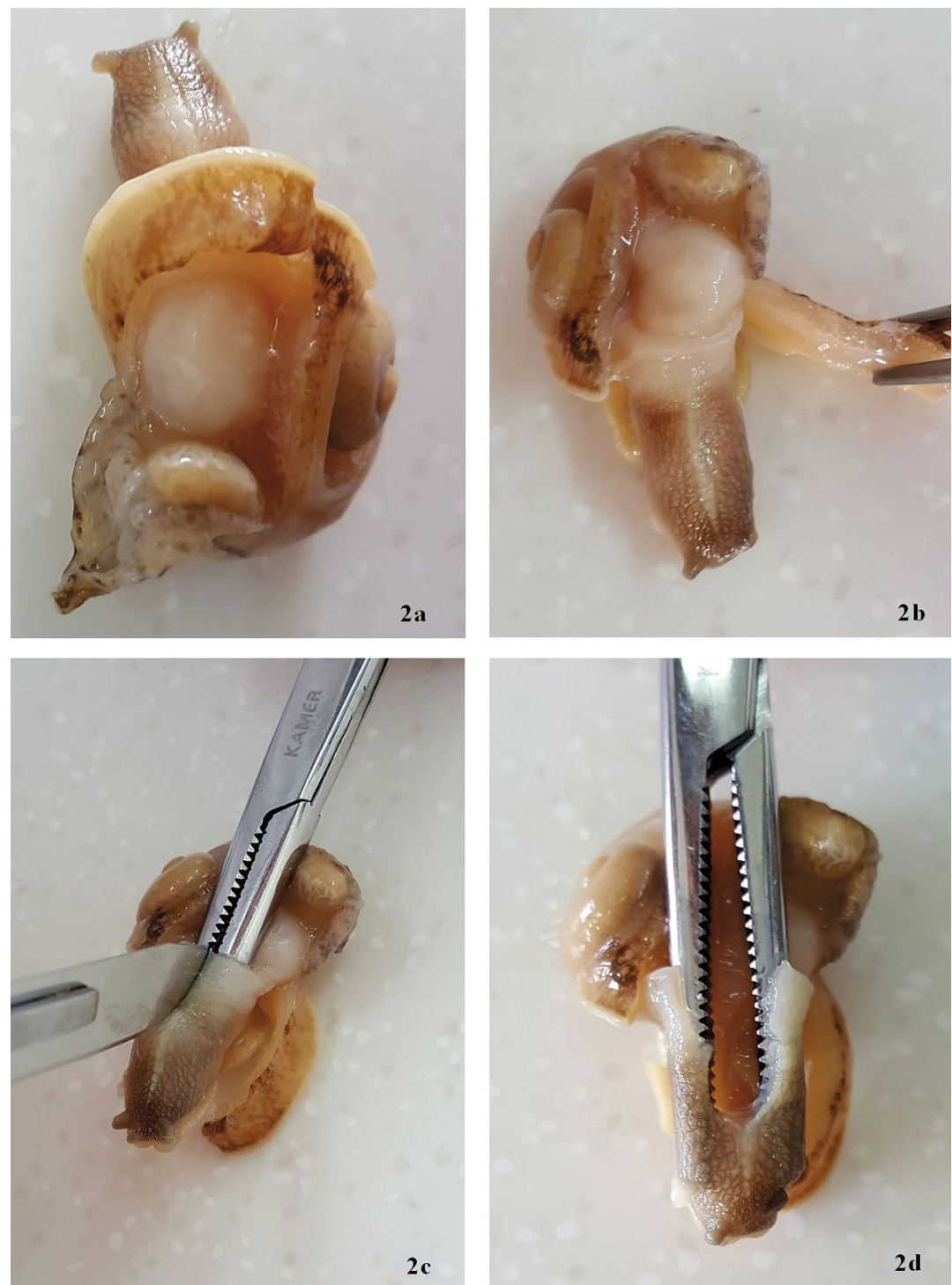

Fig. 2. C. aspersum snail dissection. Opening the body cavity. Detailed description in the text 

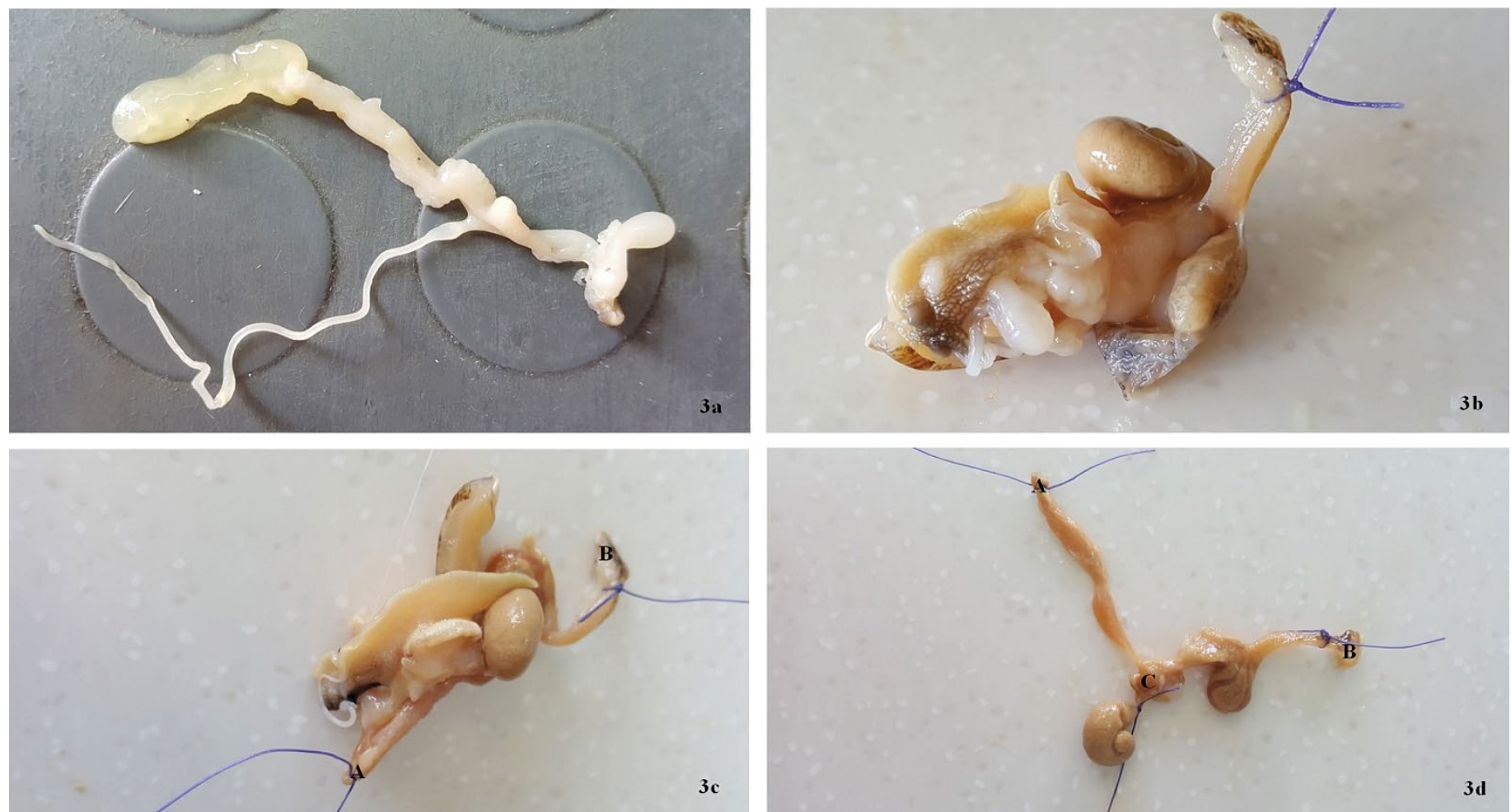

Fig. 3. Selected internal structures of the $C$. aspersum. $3 a$ - reproductive system; $3 b$ - distal segment of the gastrointestinal tract (ligation); 3c - the method of ligating both ends of the gastrointestinal tract to protect the contents; 3d - isolated gastrointestinal tract. (A) - visible proximal segment of the intestine, (B) - distal segment of the intestine, and (C) - stomach

is made possible by the action of the columellar muscle in terms of pulling the body of the snail into the shell and twisting the foot, while other movements of the animal, such as sliding out of the shell or ejecting the tentacle, are mainly related to the movement of the haemolymph in the cavities of the body. The haemolymph flow is caused by the contraction of the torso muscles. The progressive movement of the animal takes place due to the wavy contraction of the smooth muscles of the foot, while the necessary sliding movement is ensured by the secretion of mucus from the mucous glands located in the front part of the foot (2).

In order to visualize the superficial segments of the gastrointestinal tract (distal part of the intestine), an incision is made from the pneumostome to the end of the pallial lung. The pallial lung is located in the first twist of the shell, and takes the form of a cavity in the mantle lined with a thin layer of epidermis, in which numerous vessels with circulating haemolymphs pass. Snails do not exchange gas by active breathing movements, which is why they are relatively sensitive to low oxygen concentrations and the presence of harmful gases (4). Pneumostome acts as a breathing pore ensuring the flow of atmospheric air to the pallial lung. The first cut is made by placing a scissor blade in the pneumostome and then cutting about $2 \mathrm{~mm}$ from the edge of the distal part of the intestine, visible with its contents. The cut continues to the end of the pallial lung.

The second cut is made about $2 \mathrm{~mm}$ from the back edge of the mantle at a 90 degree angle to the first cut, to the end of the pallial lung. In order to expose the structures in the depths, a tissue lobe formed from the incised lung and partly from the kidney and heart is deformed (Fig. 2a). The kidney is relatively large and has a triangular shape. It consists of 2 parts, one of which is the excreting part and the other is the collecting part, the equivalent of a bladder. The urinary tract, which is connected to the end of the intestine, ends at the bladder. The ureter ends with an opening between the pneumostome and the anus. The heart of the snail consists of an atrium and a ventricle. The atrium of the heart is pearshaped with an outlet for the pulmonary vein. Two aortae leave the ventricle: the anterior and posterior aorta, which distribute the haemolymph.

In the next stage, the muscular prominence of the mantle is removed, which makes it easier to cut the dorsal part of the foot (Fig. 2b). The dorsal wall of the foot is cut towards the head in the sagittal plane and opens the front part of the foot up to the head (Fig. 2c). This operation is made much easier by inserting a pean into the created opening and continuing cutting between the arms of the tool (Fig. 2d). In this way, damage to the internal organs is avoided. The reproductive system with the protein gland is then removed (Fig. 3a). Snails of the genus Cornu are hermaphrodites. The female part produces egg cells, supplies them with coatings and tunics, and also stores the allosperm, i.e. semen received from another snail. The male part produces the sperm, supplies it with nutrients and passes it to the partner during mating. The gonad itself has a hermaphroditic character and is made up of follicles in which both egg cells and sperm are produced. External genital organs include a genital opening located on the right side of the head, visible as a whitish discolouration with a diameter of 1-2 $\mathrm{mm}$. From this pore, during mating, the male copulation organ is drawn out and directed towards the genital pore of the partner, which also acts as a vagina. Fertilisation is a crossbreeding process which takes place simultaneously in both partners. The next step is to dissect the digestive tract. The digestive system is relatively simple, with a mouth 


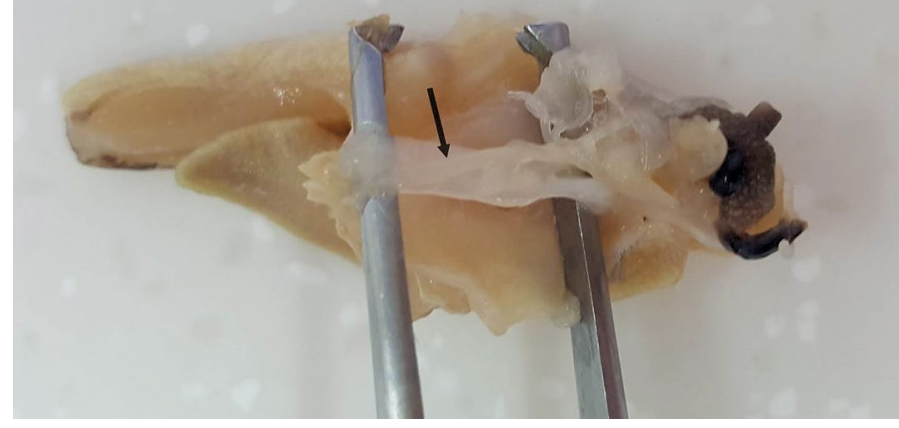

Fig. 4. Muscle system of the $C$. aspersum. Left upper corner - the structure of the mantle, below - foot visible. Structure marked with an arrow in the middle: columellar muscle

cavity located in the head part surrounded by mouth lobes $(3,6)$. Inside, there is a radula that grinds the food, which resembles a spiked tongue. Around it are jaws made of hard plates, which are used to hold the food. Behind the mouth cavity are the oesophagus and the stomach, where the ducts of the pancreatic lobes, a large gland occupying the top parts of the cochlea shell, discharge. The endocardium has an outlet near the pneumostome. Gastrointestinal tract preparation begins by separating the distal part of the large intestine from the surrounding tissues. After 1-2 cm of free intestine is obtained, its end is secured with surgical thread ties (Fig. 3b). The preparation then continues until the site where the digestive tract submerges into the hepatopancreas. Similar activities are performed on the proximal side of the gastrointestinal tract, where the intestine is not surrounded by compact tissues. These should, therefore, be pulled out gently by cutting them off from the cytopharynx (Fig. 3c). In the further part of this section, the hepatopancreas is evaluated, focusing on its consistency. The gastrointestinal tract growing into the hepatopancreas is prepared very gently (Fig. 3d). In the place of the planned incision, the lining can be placed on the intestine and the proximal and distal ends of the gastrointestinal tract can be isolated separately. In the foot emptied of internal organs, the condition of the muscles of the body walls and columellar muscle can be evaluated (Fig. 4). The aim of this article was to present a method of dissecting snails of C. aspersum spp. for the purposes of veterinary diagnostics.

\section{Results and discussion}

In a humid environment and at room temperature, the decomposition of the soft body begins after 24 hours, and is accompanied by the smell of putrefaction. Tissue liquefaction begins after 48 hours, and by days 3-5 the animal's soft body parts are impossible to assess. In a dry environment and at room temperature, the smell appears after 24 hours and the liquefaction is less evident or the body becomes dehydrated. In the case of hibernating animals, it is not possible to accurately assess the time of death. A thin and fragile shell, often without a locally coloured horny layer, is characteristic of a deficient diet or a long-term discontinuation of food intake. The folding of the shell's rim is an indicator of sexual maturity (5). The presence of a shell edge with a too-small body size suggests breeding errors: excessive stocking density, abnormal nutrition, abnormal breeding conditions, or parasitic infections due to poor breeding conditions. The presence of the epiphragm in hibernating snails is normal, but its absence indicates that hibernation has not occurred due to a too-high temperature (5). Aestivation is not a desirable phenomenon in farming, and most often indicates a too-dry mollusc farming environment (5).

The small size of the protein gland may indicate cachexia. A spongy and very fragile hepatopancreas is typical for advanced age, or may be a consequence of bacterial diseases. Low foot muscularity indicates cachexia of various origins.

According to the observations of the authors, the parenchymal organ can be collected for bacteriological cultures. Bacteriological and parasitological examinations can be performed on the intestinal contents. Muscle segments can be used for parasitological examinations (presence of parasite cysts). It is worth remembering, however, that the decomposition of the soft body parts of a snail begins very quickly, which makes it impossible to carry out many laboratory tests.

It takes approximately 10 minutes to complete a section as described above. A simple set of autopsy tools consisting of a scalpel, scissors, tweezers and pean is sufficient. During the examination, the condition of the body, individual structures and organs can be evaluated. The information obtained may be important in determining the health status of the snail, and in confirming bacterial infections or breeding errors. Thanks to the ability to perform dissections, many medical and veterinary problems can be diagnosed at an early stage, which translates into improved economic breeding indicators.

\section{References}

1. Brown K. M., Pyron M.: Introduction to Mollusca and the Class Gastropoda, [in:] Thorp J. D., Rogers C. (eds.): Ecology and General Biology, Fourth Edition, USA 2015, p. 381-421

2. McMahon R. F.: Physiological ecology of freshwater pulmonates, [in:] RussellHunter W. D. (ed.): The Mollusca. Ecology, vol. 6. Academic Press, Orlando, FL 1983, p. 359-430.

3. Ponder W. F., Lindberg D. R.: Towards a phylogeny of gastropod molluscs: an analysis using morphological characters. Zool. J. Linnean Soc. 1997, 83-265.

4.Russell-Hunter W. D.: Ecology of freshwater pulmonates, [in:] Fretter V., Peake J. (eds.): The Pulmonates. Systematics, Evolution and Ecology, vol. 2A. Academic Press, Orlando, FL 1978, p. 335-383.

5. Sadzikowski A. B., Tomczuk K.: Snails of Helix spp. - patients in veterinary practice. Med. Weter. 1997, 53, 630-638.

6. Sasaki T: Comparative anatomy and phylogeny of the recent Archaeogastropoda (Mollusca: Gastropoda). Bull. University Museum, University of Tokyo 1998, p. 1-223.

7.Ziętek J., Guz L., Winiarczyk S., Szkucik K., Ziomek M., Wysokowski M., Madany J., Adaszek t.: Study on establishing normal ranges of selected biochemical parameters of haemolymphs of Cornu aspersum maxima and Cepaea nemoralis gastropods. Polish J. Vet. Sci. 2018, 21, 445-449.

8. Ziomek M., Szkucik K., Maćkowiak-Dryka M., Paszkiewicz W., Drozd L., PyzŁukasik $R$.: Veterinary regulations for obtaining and processing edible snails. Med. Weter. 2017, 73, 819-825.

Corresponding author: Monika Ziomek, DVM, PhD, Department of Food Hygiene of Animal Origin; e-mail: monika.ziomek@up.lublin.pl 